\title{
S100B is required for high glucose-induced pro-fibrotic gene expression and hypertrophy in mesangial cells
}

\author{
CHAO-TANG CHUANG ${ }^{1}$, JINN-YUH GUH ${ }^{2,3}$, CHI-YU LU ${ }^{4}$, HUNG-CHUN CHEN ${ }^{2,3}$ and LEA-YEA CHUANG ${ }^{4}$ \\ ${ }^{1}$ Graduate Institute of Medicine and ${ }^{2}$ Department of Internal Medicine, College of Medicine, Kaohsiung Medical University; \\ ${ }^{3}$ Department of Internal Medicine, Kaohsiung Medical University Hospital, Kaohsiung Medical University; \\ ${ }^{4}$ Department of Biochemistry, College of Medicine, Kaohsiung Medical University, Kaohsiung, Taiwan, R.O.C.
}

Received July 26, 2014; Accepted November 21, 2014

DOI: $10.3892 /$ ijmm.2014.2024

\begin{abstract}
The advanced glycation end-product(AGE)-receptor for AGE (RAGE) axis induces transforming growth factor- $\beta$ (TGF- $\beta$ ) expression, cell hypertrophy and increases extracellular matrices that are indicated in the pathogenesis of diabetic nephropathy (DN). RAGE binds to numerous ligands besides AGE, including S100B. In the present study, the roles of S100B in high glucose-induced p2 $1^{\mathrm{WAF} 1}$, extracellular matrices, TGF- $\beta 1$ and cell hypertrophy in mouse mesangial (MES13) cells were investigated. High glucose $(30 \mathrm{mM})$ time-dependently (24-72 h) induced S100B expression. High glucose and exogenous $\mathrm{S} 100 \mathrm{~B}(1 \mu \mathrm{M})$ time-dependently increased $p 21^{W A F I}$ gene transcription and protein expression, increased type IV collagen and fibronectin protein expression, and $T G F-\beta$ gene transcription and bioactivity. Exogenous S100B also time-dependently activated the extracellular regulated kinases (ERK1/2), p38 kinase and c-Jun N-terminal kinase (JNK) signaling pathways. Exogenous S100B-induced $T G F-\beta$ gene transcription and bioactivity were attenuated by SB203580 (p38 kinase inhibitor) and PD98059 (ERK1/2 inhibitor). Finally, the knockdown of $S 100 B$ by small interfering RNA (siRNA) attenuated high glucose-induced $T G F-\beta$ gene transcription and bioactivity, type IV collagen and fibronectin protein expression and $\mathrm{p} 21^{\mathrm{WAF} 1}$ protein expression. Thus, S100B induced TGF- $\beta$ via the ERK1/2 and $\mathrm{p} 38$ kinase pathways in mesangial cells. Additionally, high glucose-induced pro-fibrotic genes ( $T G F-\beta$, type IV collagen and fibronectin) and cell hypertrophy-related $\mathrm{p} 21^{\mathrm{WAF} 1}$ are dependent on S100B.
\end{abstract}

Correspondence to: Dr Lea-Yea Chuang, Department of Biochemistry, College of Medicine, Kaohsiung Medical University, 100 Zihyou 1st Road, Kaohsiung 807, Taiwan, R.O.C.

E-mail: chuangly@gmail.com

Dr Jinn-Yuh Guh, Department of Internal Medicine, College of Medicine, Kaohsiung Medical University, 100 Zihyou 1st Road, Kaohsiung 807, Taiwan, R.O.C.

E-mail: guhjy@kmu.edu.tw

Key words: $S 100 B$, transforming growth factor- $\beta$, high glucose, mesangial cells, diabetic nephropathy

\section{Introduction}

Chronic hyperglycemia increases advanced glycation end-products (AGE) that bind to the receptor for AGE (RAGE). The AGE-RAGE axis induces transforming growth factor- $\beta$ (TGF- $\beta$ ), cell hypertrophy and increases extracellular matrices that are implicated in the pathogenesis of diabetic nephropathy (DN) (1-4). RAGE engagement by the specific ligands triggers DN-related signaling pathways, including extracellular regulated kinases (ERK1/2), p38 kinase and c-Jun N-terminal kinase (JNK) (5).

High glucose increases RAGE expression in mesangial cells (6) and the pivotal role of RAGE in DN can be illustrated by the finding that glomerular RAGE expression is increased in diabetic mice (7). Additionally, RAGE overexpression exacerbates, whereas RAGE deletion attenuates experimental DN $(3,8)$. TGF- $\beta$ is another central player in DN as it is pivotal in cell hypertrophy and increased extracellular matrices in DN $(1,4)$. Diabetic renal hypertrophy is associated with cell cycle arrest and increased glomerular $\mathrm{p} 21^{\mathrm{WAF} 1}$ (cyclin-dependent kinase inhibitor) expression $(9,10)$, whereas p $21^{\mathrm{WAF} 1}$-knockout mice are protected from glomerular hypertrophy despite increased TGF- $\beta$ levels (11).

RAGE binds to a number of ligands besides AGE, including S100B (a member of the S100/calgranulin family) (12). S100B is mainly expressed and secreted by the neural cells (12), whereas cerebral levels of S100B are increased in the diabetic rats (13). Notably, in two previous studies, it was found that S100B increases TGF- $\beta 1$ and fibronectin expression, while activating ERK1/2 and p38 kinase pathways in mesangial cells $(14,15)$. However, the roles of endogenous S100B in high glucose-induced effects are not known.

Therefore, the roles of S100B in high glucose-induced $\mathrm{p} 21^{\mathrm{WAF} 1}$, extracellular matrices, TGF- $\beta 1$ and cell hypertrophy in mouse mesangial (MES13) cells were investigated in the present study. Additionally, the molecular mechanisms of S100B-induced TGF- $\beta$ activity were assessed in terms of the ERK1/2, p38 kinase and JNK pathways.

\section{Materials and methods}

Materials. Dimethyl sulfoxide, PD98059 (ERK1/2 inhibitor), SB203580 (p38 kinase inhibitor), SP600125 (JNK inhibitor) 
and SB431542 (type ITGF- $\beta$ receptor inhibitor) were purchased from the Sigma-Aldrich Co. (St. Louis, MO, USA). S100B was purchased from the Abcam Co. (Cambridge, MA, USA).

Cells. The mouse mesangial cell line (MES13 cells, BCRC-60366) was purchased from the Bioresource Collection and Research Center (Hsinchu, Taiwan), which obtained the cells (CRL-1927) from the American Type Culture Collection (Manassas, VA, USA). Cells were used within 30 passages of the original passage and were cultured in a 3:1 mixture of Dulbecco's modified Eagle's medium and Ham's F12 medium (final glucose $6.67 \mathrm{mM}$ ), $14 \mathrm{mM}$ HEPES, $1 \%$ penicillin/streptomycin (Gibco, Grand Island, NY, USA) and 5\% fetal bovine serum (FBS; Gibco) in $5 \% \mathrm{CO}_{2}$ at $37^{\circ} \mathrm{C}$. MES13 cells were serum-starved for $16 \mathrm{~h}$ before treatment with S100B $(1 \mu \mathrm{M})$ or the signaling pathway inhibitors.

Immunoblotting. Total cell lysates were harvested, resolved by $10 \%$ SDS-polyacrylamide gel electrophoresis, and were subsequently transferred to Protran membranes $(0.45 \mathrm{~mm}$; Schieicher \& Schuell, Keene, NH, USA). The membranes were blocked in blocking solution and subsequently probed with the following primary antibodies: S100B (ab41548, rabbit anti-rat) and col4 $\alpha 1$ (ab6586, rabbit anti-human; Abcam Co.), p21 ${ }^{\mathrm{WAF} 1}$ (sc-397, goat anti-human) and glyceraldehyde 3-phosphate dehydrogenase (GAPDH) (sc25778, rabbit anti-human; Santa Cruz Biotechnology, Inc., Santa Cruz, CA, USA), fibronectin (AB1954, rabbit anti-rat; Chemicon International, Inc., Temecula, CA, USA), $\alpha$-tubulin (MS-581-P0, mouse antichicken monoclonal antibody; Thermo Fisher Scientific, Inc., Fremont, CA, USA), ERK1/2 (9102, rabbit anti-rat), p-ERK1/2 (4370, rabbit anti-human; Thr202/Tyr204), p38 kinase (9212, rabbit anti-human), p-p38 kinase (4631, rabbit anti-human; Thr180/Try182), JNK (9258, rabbit anti-human) and p-JNK (9251, rabbit anti-human; Thr183/Tyr185) (Cell Signaling Technology, Inc., Beverly, MA, USA). The membrane was subsequently incubated in 4,000x diluted horseradish peroxidase-conjugated goat anti-rabbit or anti-mouse secondary antibody. The protein bands were detected using the enhanced chemiluminescence system. The intensity of the immunoblot bands was quantified by densitometric analysis. Results are expressed as the ratio of intensity of the protein of interest to that of $\alpha$-tubulin or the indicated protein from the same sample.

Reverse transcriptase-quantitative polymerase chain reaction $(R T-q P C R)$. Total RNA was extracted using the REzol reagent (PT-KP200CT) according to the manufacturer's instructions (Protech Technologies, Inc., Taipei, Taiwan). Briefly, cDNA was synthesized from $1 \mu \mathrm{g}$ RNA with the reverse transcriptase system (Promega Corp., Madison, WI, USA). RT-qPCR of the obtained cDNA was performed in triplicate on an ABI 7900 Fast RT-PCR System (Applied Biosystems, Warrington, Cheshire, UK) using SYBR Green for qPCR (Protech Corp.). The primers used were: mouse $S 100 B$ forward, 5'-TGGTTGCCCTCATTGATGTCT-3' and reverse, 5'-CTCGTTGTTGATAAGCTCCTTCAG-3'; and mouse 18S $r R N A$ forward, 5'-CCAGTAAGTGCGGGTCATAAGC-3' and reverse, 5'-CCTCACTAAACCATCCAATCGG-3'.
Enzyme-linked immunosorbent assay (ELISA). Medium S100B was measured using the S100B ELISA kit (Millipore Corp., Billerica, MA, USA) according to the manufacturer's instructions. The absorbance at $450 \mathrm{~nm}$ was recorded by the ELISA reader. The level of secreted S100B was calculated for one million cells.

Luciferase reporter plasmid transfection. The p21 promoter reporter construct p21P was a gift from Dr X.F. Wang (Department of Pharmacology, Duke University Medical Center, Durham, NC, USA) (16). The human TGF- $\beta 1$ promoter-luciferase construct phTG5-luc was a gift from Dr J.L. Virelizier (Unité d'Immunologie Virale, Institut Pasteur, Paris, France) (17). The TGF- $\beta$ bioactivity reporter p3TP-lux was a gift from Dr J. Massagué (Memorial Sloan-Kettering Cancer Center, New York, NY, USA) (18). Plasmids were transiently transfected into the MES13 cells in 6-well plates $\left(1 \times 10^{4}\right.$ cells/well) using the TurboFect reagent (Fermentas Inc., Israel). Medium containing 5\% FBS was added $24 \mathrm{~h}$ later and cells were treated with high glucose or $1 \mu \mathrm{M} \mathrm{S100B}$ for the indicated times. Cells were lysed and luciferase activity was measured by the Dynatech ML1000 luminometer (Dynatech Laboratories, Inc., Chantilly, VA, USA).

Cell hypertrophy. Cells were grown in 6-well plates until approximately $50 \%$ confluent and were subsequently made quiescent for $16 \mathrm{~h}$ in the medium containing $0.1 \% \mathrm{FBS}$. The cultures were treated with HG $(30 \mathrm{mM})$ and S100B $(1 \mu \mathrm{M})$ for the indicated times, following which the cells were trypsinized, washed twice with phosphate-buffered saline (PBS) and counted using a hemocytometer with trypan blue staining. Equal numbers of cells were lysed in buffer $[0.1 \%(\mathrm{wt} / \mathrm{vol})$ SDS, $0.5 \%(\mathrm{wt} / \mathrm{vol})$ sodium deoxycholate and $1.0 \%(\mathrm{wt} / \mathrm{vol})$ Nonidet P-40, in PBS]. The total protein content was measured by the Bio-Rad protein assay kit (Bio-Rad, Hercules, CA, USA). Cell hypertrophy was assessed by steady-state total protein $(\mu \mathrm{g}) / 10^{4}$ cells.

Small interfering RNA (siRNA) transfection. S100B siRNA (sense, 5'-GCC CUC AUU GAU GUC UUC CAC CAG U-3' and anitsense, 5'-ACU GGU GGA AGA CAU CAA UGA GGG C-3') were purchased from the Invitrogen Corp. (Grand Island, NY, USA). Negative control siRNA (Trilencer-27 siRNA) was from the OriGene Technologies Inc. (Rockville, MD, USA). We transfected $50 \mathrm{nM}$ siRNA into cells in 6-well plates $\left(10 \times 10^{4}\right.$ cells/well) by using the TurboFect reagent (Fermentas Inc.). Cells were exchanged with fresh 5\% FBS-containing medium $24 \mathrm{~h}$ after transfection.

Statistics. Data are expressed as the means \pm standard error of the mean. In vitro experimental data were collected from $\geq 3$ repeated experiments. One-way analysis of variance followed by post-hoc Dunnett tests was used for the comparison between the treated and control groups. $\mathrm{P}<0.05$ was considered to indicate a statistically significant difference.

\section{Results}

High glucose increases $S 100 B$ protein and $m R N A$ expression in mes13 cells. S10OB mRNA was measured by RT-qPCR, while 
A

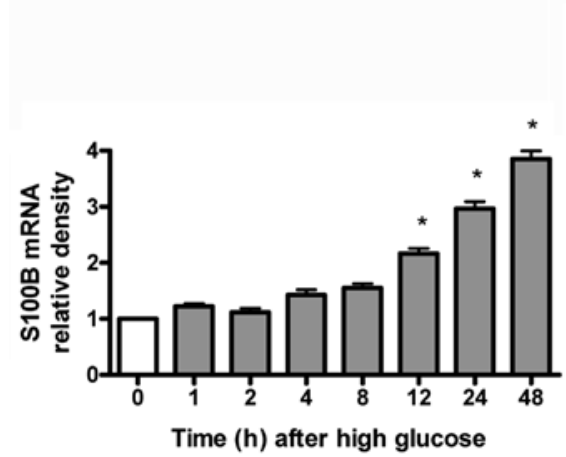

B

S100B

a-tubulin
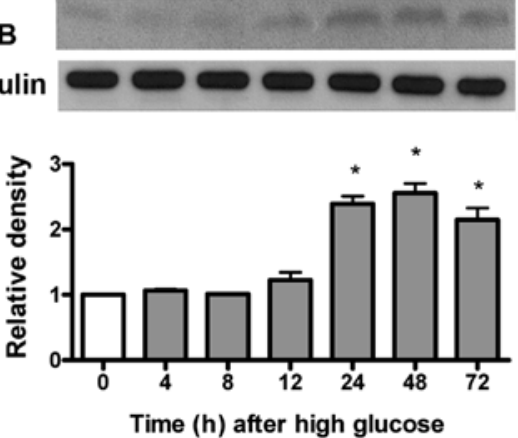

C

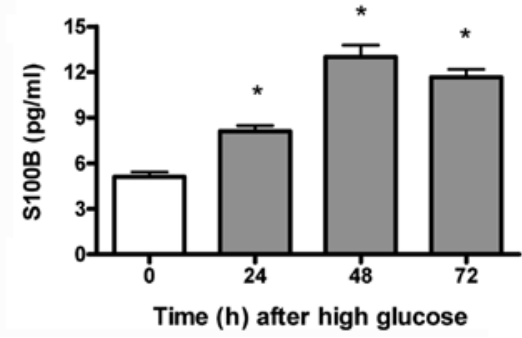

Figure 1. High glucose increases S100B protein and mRNA expression in MES13 cells. Serum-fasted cells were exposed to normal glucose (5.5 mM, open bars) or high glucose (30 mM, closed bars). (A) $S 100 B$ mRNA was measured by RT-qPCR. Time-dependent (1-48 h) effects of high glucose on $S 100 B$ mRNA expression are shown. (B) S100B protein was measured by immunoblotting and normalized to $\alpha$-tubulin. Time-dependent (4-72 h) effects of high glucose on S100B protein expression are shown. (C) Medium S100B was measured using the S100B ELISA kit. Time-dependent (24-72 h) effects of high glucose on medium S100B concentration are shown. Data are expressed as the means \pm standard error of the mean of three independent experiments. ${ }^{*} \mathrm{P}<0.05 \mathrm{vs} .0 \mathrm{~h}$.

A

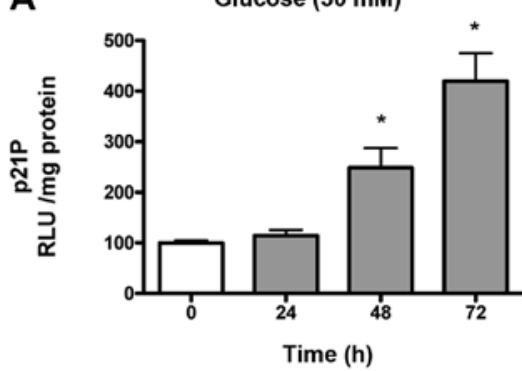

C

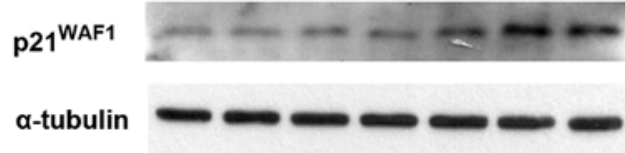

궁

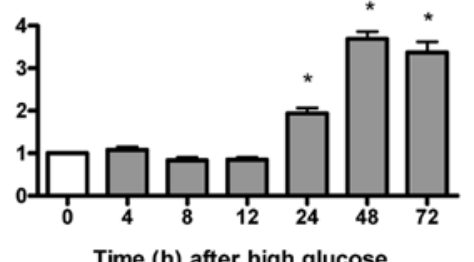

Time (h) after high glucose

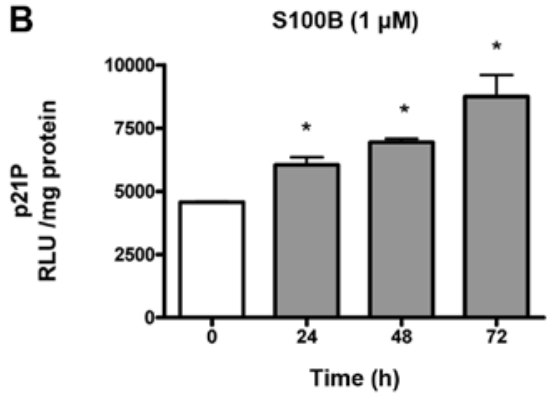

D
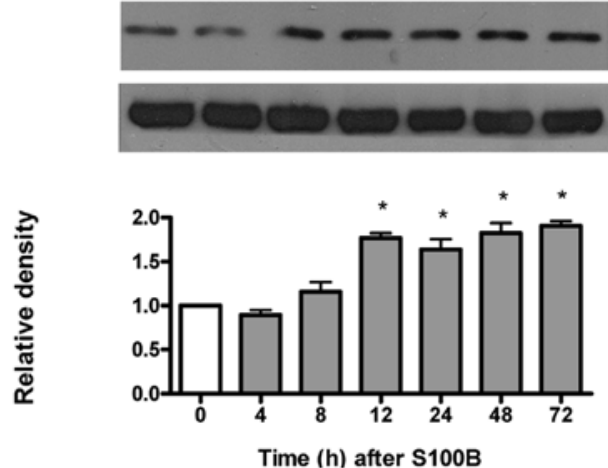

Figure 2. High glucose and S100B time-dependently increase $p 21^{\text {WAFI }}$ gene transcription and protein expression. Transcriptional activity of $p 21^{\text {WAFI }}$ was measured by transient transfection of the $\mathrm{p} 21^{\mathrm{WAF} 1}$ promoter reporter construct $\mathrm{p} 21 \mathrm{P}$. Protein expression of $\mathrm{p} 21^{\mathrm{WAF} 1}$ was measured by immunoblotting and normalized to $\alpha$-tubulin. Time-dependent $(24-72 \mathrm{~h})$ effects of (A) high glucose (30 mM, closed bars) and (B) S100B (1 $\mu \mathrm{M}$, closed bars) on $p 21^{\text {WAFI }}$ gene transcription was expressed as the relative light units (RLU). Time-dependent (4-72 h) effects of (C) high glucose (30 mM, closed bars) and (D) S100B (1 $\mu \mathrm{M}$, closed bars) on $\mathrm{p} 21^{\mathrm{WAF} 1}$ protein expression. Data are expressed as the means \pm standard error of the mean of three independent experiments. ${ }^{*} \mathrm{P}<0.05 \mathrm{vs} .0 \mathrm{~h}$.

S100B protein was measured by immunoblotting and ELISA. As shown in Fig. 1, high glucose $(30 \mathrm{mM})$ time-dependently (12-48 h) increased $S 100 B$ mRNA (Fig. 1A) and time-dependently (24-72 h) increased S100B protein (Fig. 1B) expression and medium S100B protein levels (Fig. 1C).

High glucose and $S 100 B$ time-dependently increase p21 WAFI gene transcription and protein expression. High glucose-induced cell hypertrophy is associated with increased p $21^{\mathrm{WAF} 1}$ expression in mesangial cells (10). Gene transcriptional activity of the $p 21^{W A F I}$ gene was measured by $\mathrm{p} 21 \mathrm{P}$, while protein expression was measured by immunoblotting. As shown in Fig. 2A, high glucose time-dependently (48-72 h) increased the $p 21^{W A F 1}$ gene transcriptional activity. Similarly, S100B $(1 \mu \mathrm{M})$ time-dependently $(24-72 \mathrm{~h})$ increased the $p 21^{\text {WAFI }}$ gene transcriptional activity (Fig. 2B). As shown in Fig. 2C, high glucose time-dependently $(48-72 \mathrm{~h})$ increased $\mathrm{p} 21^{\mathrm{WAF} 1}$ protein expression. Similarly, S100B $(1 \mu \mathrm{M})$ time-dependently $\left(12-72 \mathrm{~h}\right.$ ) increased $\mathrm{p} 21^{\mathrm{WAF} 1}$ protein expression (Fig. 2D).

High glucose and S100B time-dependently increase type IV collagen and fibronectin protein expression. Type IV collagen 

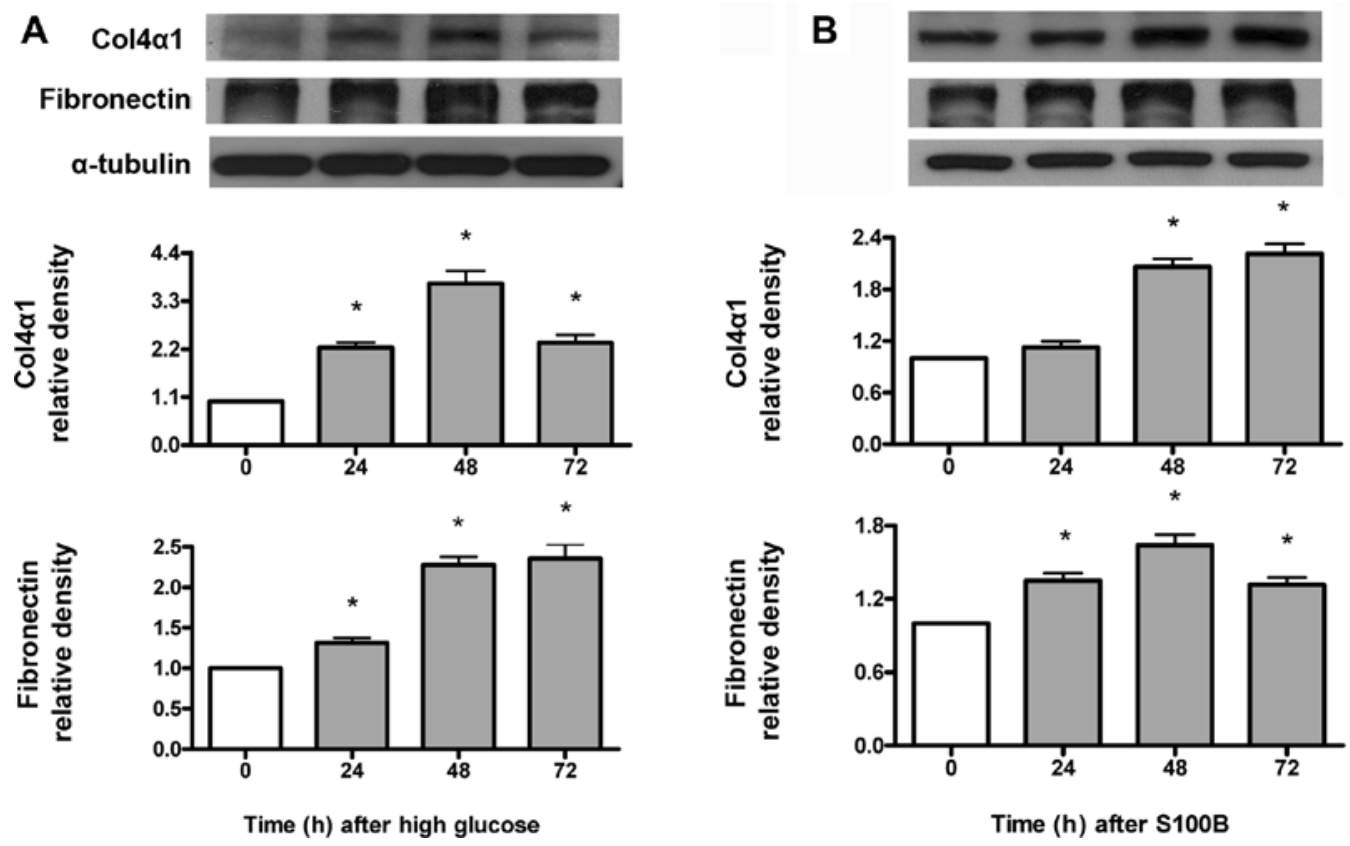

Figure 3. High glucose and S100B time-dependently increase type IV collagen and fibronectin protein expression. Expression of type IV collagen (col4a1) and fibronectin protein was measured by immunoblotting and normalized to $\alpha$-tubulin. Time-dependent (24-72 h) effects of (A) high glucose (30 mM, closed bars) and (B) S100B ( $1 \mu \mathrm{M}$, closed bars) on col4 $\alpha 1$ and fibronectin protein expression. Data are expressed as the means \pm standard error of the mean of three independent experiments. ${ }^{*} \mathrm{P}<0.05$ vs. $0 \mathrm{~h}$.

A

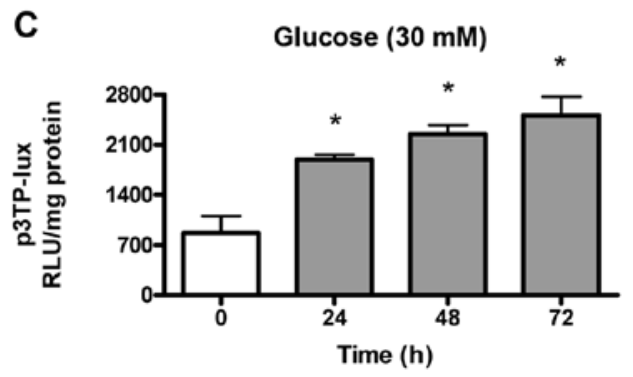

B

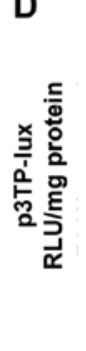

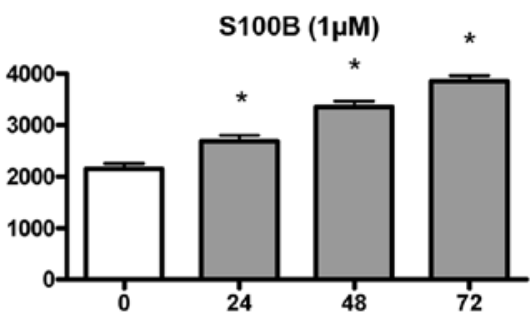

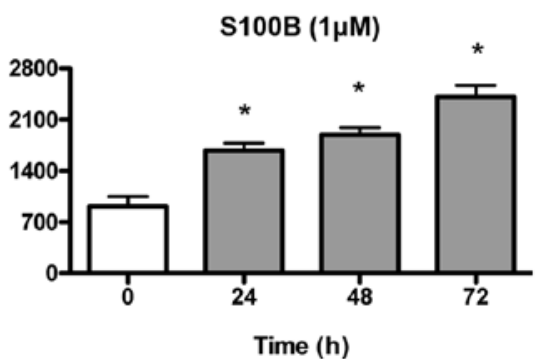

Figure 4. High glucose and S100B time-dependently induce $T G F-\beta$ gene transcription and bioactivity. TGF- $\beta$ transcriptional activity or bioactivity (expressed as the relative light units, RLU) were measured by transient transfection of phTG5-luc (TGF- $\beta$ promoter plasmid) or p3TP-lux (TGF- $\beta$ bioactivity reporter plasmid), respectively. Time-dependent (24-72 h) effects of (A) high glucose (30 mM, closed bars) or (B) S100B (1 $\mu \mathrm{M}$, closed bars) on TGF- $\beta$ transcriptional activity. Effects of (C) high glucose (30 mM, closed bars) and (D) S100B (1 $\mu \mathrm{M}$, closed bars) on TGF- $\beta$ bioactivity. Data are expressed as the means \pm standard error of the mean of three independent experiments. ${ }^{*} \mathrm{P}<0.05$ vs. 0 h. TGF- $\beta$, transforming growth factor $\beta$.

and fibronectin protein expression was measured by immunoblotting. As shown in Fig. 3A, high glucose $(30 \mathrm{mM})$ increased type IV collagen and fibronectin protein expression at $24-72 \mathrm{~h}$. Similarly, S100B $(1 \mu \mathrm{M})$ increased type IV collagen protein expression at $48-72 \mathrm{~h}$, but increased fibronectin protein expression at 24-72 h (Fig. 3B).
High glucose and S10OB time-dependently induce TGF- $\beta$ gene transcription and bioactivity. Gene transcriptional activity of the TGF- $\beta$ gene was measured by transient transfection of phTG5-luc, while TGF- $\beta$ bioactivity was measured by transient transfection of p3TP-lux. As shown in Fig. 4A and B, high glucose $(30 \mathrm{mM})$ and S100B $(1 \mu \mathrm{M})$ time-dependently $(24-72 \mathrm{~h})$ 

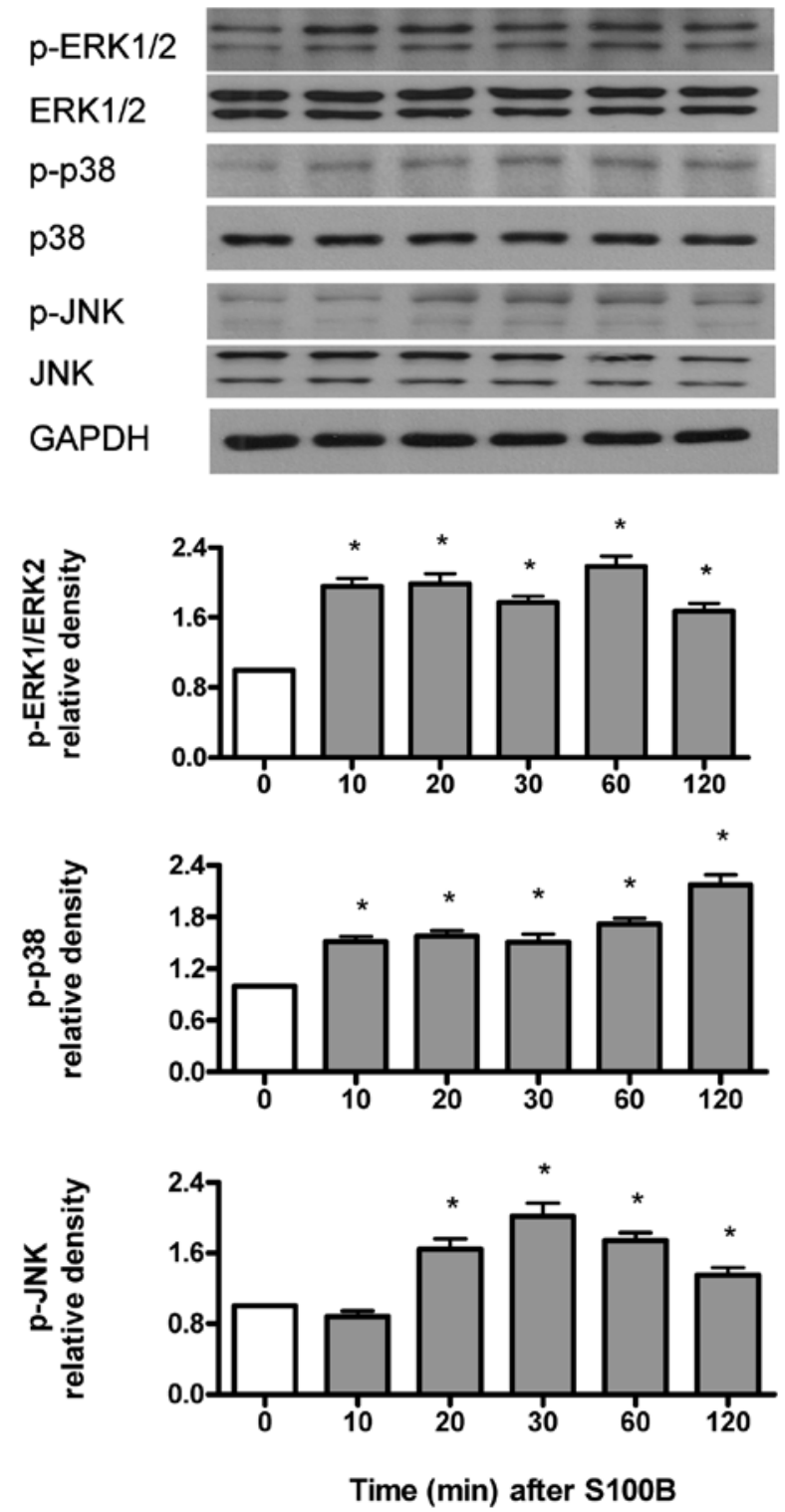

Figure 5. S100B time-dependently activates ERK1/2, p38 and JNK kinases. Phospho-ERK1/2 (p-ERK1/2), ERK1/2, p-p38 kinase, p38 kinase, p-JNK, JNK and GAPDH were measured by immunoblotting. Expression of phosphorylated proteins was normalized to that of the respective unphosphorylated proteins. Time-dependent (10-120 min) effects of S100B $(1 \mu \mathrm{M})$ on p-ERK1/2, p-p38 and $\mathrm{p}$-JNK expression are shown. Data are expressed as the means \pm standard error of the mean of three independent experiments. ${ }^{*} \mathrm{P}<0.05$ vs. 0 h. ERK1/2, extracellular regulated kinases; JNK, c-Jun N-terminal kinase.

increased the TGF- $\beta$ gene transcriptional activity. As shown in Fig. $4 \mathrm{C}$ and D, high glucose $(30 \mathrm{mM})$ and S100B $(1 \mu \mathrm{M})$ time-dependently (24-72 h) increased TGF- $\beta$ bioactivity.

S100B time-dependently activates ERK1/2, p38 and JNK kinases. p-ERK1/2, p-p38 kinase and p-JNK were measured by immunoblotting and were normalized to their respective unphosphorylated forms. As shown in Fig. 5, S100B $(1 \mu \mathrm{M})$ increased p-ERK1/2 and p-p38 kinase at 10-120 min, but increased p-JNK at 20-120 min.

S100B-induced TGF- $\beta$ gene transcription and TGF- $\beta$ bioactivity are dependent on ERK1/2, p38 and TGF- $\beta$ receptors. Gene transcriptional activity of the TGF- $\beta$ gene was measured
A

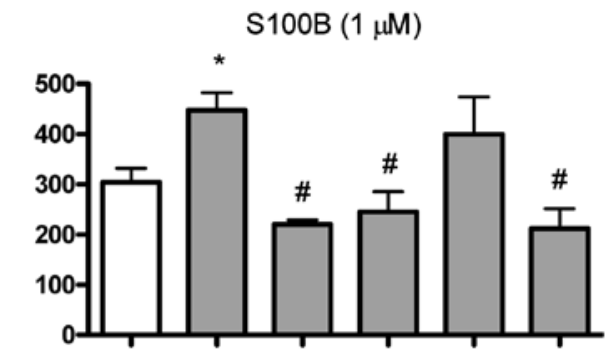

B S100B $(1 \mu \mathrm{M})$

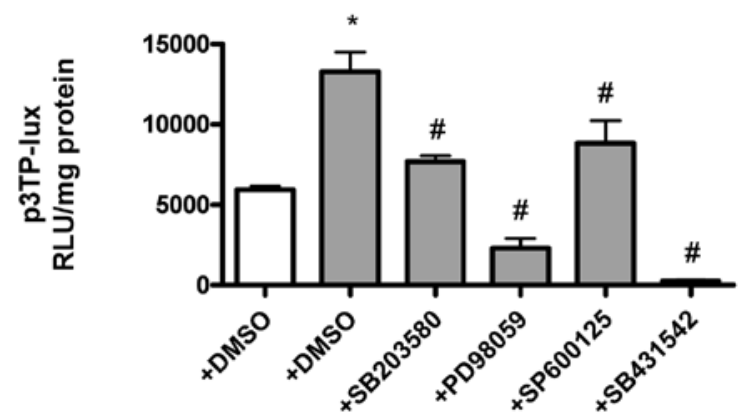

Figure 6. S100B-induced $T G F-\beta$ gene transcription and bioactivity are dependent on ERK1/2, p38 and TGF- $\beta$ receptor. TGF- $\beta$ transcriptional activity or bioactivity (expressed as the relative light units, RLU) were measured by transient transfection of phTG5-luc (TGF- $\beta$ promoter plasmid) or p3TP-lux (TGF- $\beta$ bioactivity reporter plasmid), respectively. SB203580, PD98059, SP600125 and SB431542 were dissolved in dimethyl sulfoxide (DMSO) (final concentration $0.1 \%)$. (A) Effects of SB203580 $(10 \mu \mathrm{M}$, p38 inhibitor, pre-treated for $1 \mathrm{~h})$, PD98059 $(10 \mu \mathrm{M}$, ERK1/2 inhibitor, pre-treated for $1 \mathrm{~h})$, SP600125 (10 $\mu \mathrm{M}$, JNK inhibitor, pre-treated for $1 \mathrm{~h})$ and SB431542 $(10 \mu \mathrm{M}$, TGF- $\beta$ receptor type I inhibitor, pre-treated for $1 \mathrm{~h})$ on S100B $(1 \mu \mathrm{M}$, closed bars)-induced $T G F-\beta$ transcription at $24 \mathrm{~h}$. (B) Effects of SB203580, PD98059, SP600125 and SB431542 on S100B (1 $\mu \mathrm{M}$, closed bars)-induced TGF- $\beta$ bioactivity at $24 \mathrm{~h}$. Data are expressed as the means \pm standard error of the mean of three independent experiments. ${ }^{*} \mathrm{P}<0.05$ vs. lane $1 .{ }^{*} \mathrm{P}<0.05$ vs. lane 2 . TGF- $\beta$, transforming growth factor- $\beta$; ERK1/2, extracellular regulated kinases; JNK, c-Jun N-terminal kinase.

by phTG5-luc, while TGF- $\beta$ bioactivity was measured by p3TP-lux. SB203580 (p38 kinase inhibitor), PD98059 (ERK1/2 inhibitor) and SB431542 (type I TGF- $\beta$ receptor inhibitor) attenuated S100B $(1 \mu \mathrm{M})$-induced $T G F-\beta$ gene transcriptional activity (Fig. 6A) and TGF- $\beta$ bioactivity (Fig. 6B) at 24 h. By contrast, SP600125 (JNK inhibitor) only attenuated S100B $(1 \mu \mathrm{M})$-induced TGF- $\beta$ bioactivity (Fig. 6B), but not $T G F-\beta$ gene transcriptional activity (Fig. 6A) at $24 \mathrm{~h}$.

High glucose-induced TGF- $\beta$ and pro-fibrotic genes are dependent on $S 100 B$. Gene transcriptional activity of the $T G F-\beta$ gene was measured by transient tranfection of phTG5-luc, while TGF- $\beta$ bioactivity was measured by p3TP-lux. Type IV collagen, fibronectin, S100B and $\mathrm{p} 21^{\mathrm{WAF} 1}$ proteins were measured by immunoblotting. The role of S100B was measured by $S 100 B$ siRNA. S100B (but not the scrambled) siRNA attenuated high glucose-induced $T G F-\beta$ gene transcriptional activity (Fig. 7A) and bioactivity (Fig. 7B) at $24 \mathrm{~h}$. Additionally, S100B (but not the scrambled) siRNA increased high glucose-induced type IV collagen, fibronectin, S100B and $\mathrm{p} 21^{\mathrm{WAF} 1}$ protein expression at $48 \mathrm{~h}$ (Fig. 7C). Finally, $S 100 B$ (but not the scrambled) siRNA 
A

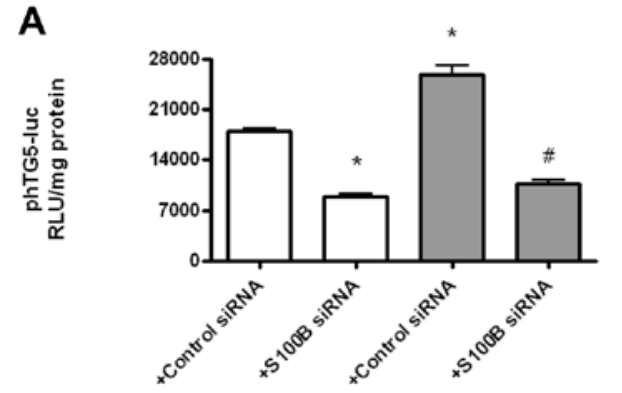

C

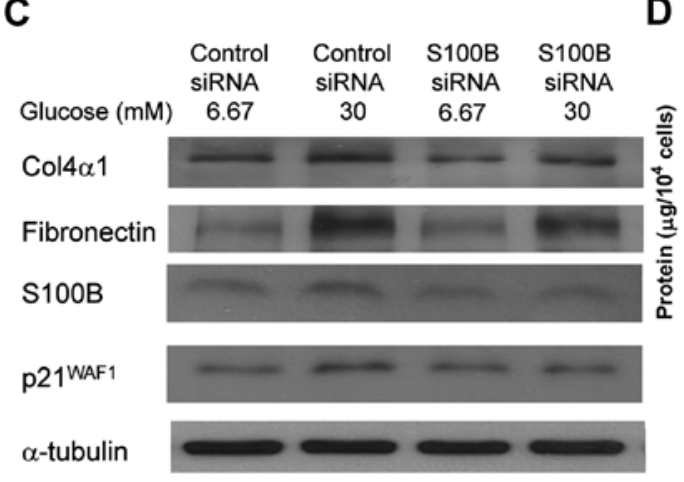

D
B

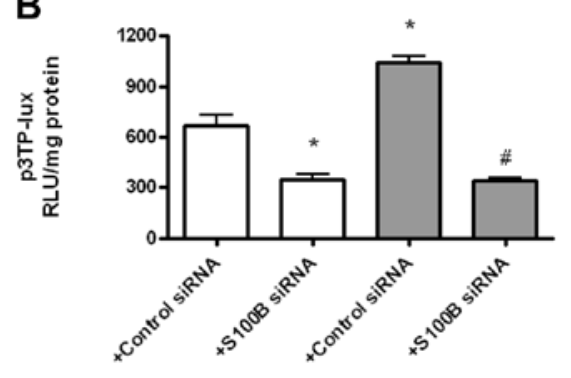

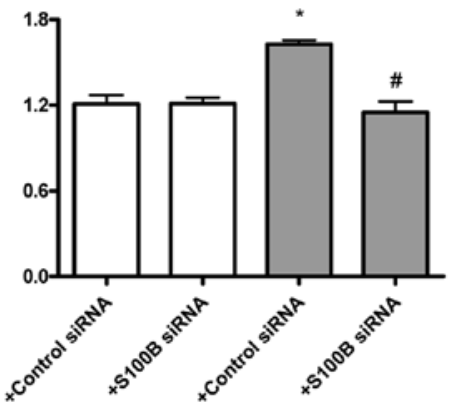

Figure 7. High glucose-induced TGF- $\beta$ and pro-fibrotic genes are dependent on S100B. S100B siRNA (50 nM) was transiently transfected into cells. TGF- $\beta$ transcriptional activity or bioactivity (expressed as the relative light units, RLU) was measured by transient transfection of phTG5-luc (TGF- $\beta$ promoter plasmid) or p3TP-lux (TGF- $\beta$ bioactivity reporter plasmid), respectively. Expression of type IV collagen (col4 $\alpha 1)$, fibronectin, S100B and p2 ${ }^{\text {WAF1 }}$ proteins was measured by immunoblotting and normalized to $\alpha$-tubulin. Cell hypertrophy was assessed by total protein $(\mu \mathrm{g}) / 10^{4} \mathrm{cells}$. Effects of $S 100 B$ siRNA on high glucose (30 mM, closed bars)-induced (A) $T G F-\beta$ gene transcriptional activity and (B) bioactivity at $24 \mathrm{~h}$. Effects of $S 100 B$ siRNA on high glucose-induced (C) col4 $\alpha 1$, fibronectin, S100B and p21 ${ }^{\mathrm{WAF} 1}$ proteins and (D) cell hypertrophy at $48 \mathrm{~h}$. Data are expressed as the means \pm standard error of the mean of three independent experiments. ${ }^{*} \mathrm{P}<0.05$ vs. lane $1 .{ }^{\#} \mathrm{P}<0.05$ vs. lane 3 . TGF- $\beta$, transforming growth factor- $\beta$; siRNA, small interfering RNA.

attenuated high glucose-induced cell hypertrophy (Fig. 7D) at $48 \mathrm{~h}$.

\section{Discussion}

To the best of our knowledge, this is the first study to demonstrate that high glucose increased $\mathrm{S} 100 \mathrm{~B}$ in mesangial cells and that high glucose and S100B increased p21 ${ }^{\mathrm{WAF} 1}$, type 4 collagen, fibronectin and TGF- $\beta$ activity. Additionally, S100B-induced TGF- $\beta$ is dependent on ERK1/2 and p38 kinase, whereas high glucose-induced expression of $\mathrm{p} 21^{\mathrm{WAF} 1}$, type IV collagen, fibronectin and TGF- $\beta$ and cell hypertrophy are dependent on S100B. These findings shed light on the roles of S100B in DN.

The finding that high glucose increased $S 100 B$ expression in mesangial cells is similar to two previous studies showing increased $S 100 B$ mRNA levels in diabetic human glomeruli (19) or diabetic rat renal cortex (20) in the Gene Expression Omnibus microarray database (21), although the original studies did not mention it. High glucose and exogenous $\mathrm{S} 100 \mathrm{~B}$ were also found to induce the $p 21^{W A F I}$ gene transcription and protein expression, type IV collagen and fibronectin expression and $T G F-\beta$ gene transcription and bioactivity. These findings prompted us to further elucidate the roles of $\mathrm{S} 100 \mathrm{~B}$ in high glucose-induced effects.

High glucose-induced $T G F-\beta$ gene transcription and bioactivity, $p 21^{W A F 1}$ gene transcription and protein expression, and type IV collagen and fibronectin expression are dependent on S100B. In addition, high glucose-induced cell hypertrophy is also dependent on S100B. As S100B is a specific ligand for RAGE (3), it is likely that the above high glucose-induced effects are dependent on RAGE. However, it is also likely that intracellular S100B acts without engaging RAGE (22).

ERK1/2, p38 kinase and JNK pathways have been indicated in the pathogenesis of DN $(1,5)$. These pathways are also the downstream targets of the RAGE signaling (5). S100B activated the ERK1/2, p38 kinase and JNK pathways in the present study. Additionally, S100B-induced TGF- $\beta$ transcription and bioactivity are dependent on the TGF- $\beta$ receptor and the ERK1/2 and p38 kinase pathways. These findings are compatible with the notion of the auto-induction of TGF- $\beta$ (23) and also corroborate two previous findings that TGF- $\beta 1$ induction is dependent on ERK1/2 and p38 kinase in mesangial cells $(24,25)$. By contrast, S100B-induced TGF- $\beta$ bioactivity (but not gene transcription) is dependent on the JNK pathway. This finding is compatible with the notion that JNK is a part of the TGF- $\beta$ non-Smad signaling pathways (26).

In conclusion, S100B induced TGF- $\beta$ via the ERK1/2 and p38 kinase pathways. The significance of high glucose-induced S100B is demonstrated by the findings that high glucose-induced pro-fibrotic genes (TGF- $\beta$, type IV collagen and fibronectin) and cell hypertrophy-related p $21^{\text {WAF1 }}$ are dependent on S100B. Thus, S100B may be a novel target for the treatment of DN. 


\section{Acknowledgements}

This study was supported in part by grants from the National Science Council of Taiwan (101-2314-B-037-036-MY3 to L.-Y.C. and 102-2314-B-037-011-MY3 to J.-Y.G.) and the Center for Lipid and Glycomedicine Research (KMU-TP103D16 to L.-Y. C.). The authors would like to thank Dr X.F. Wang, Dr J.L. Virelizier and Dr J. Massagué for the gifts of the plasmids.

\section{References}

1. Gnudi L: Cellular and molecular mechanisms of diabetic glomerulopathy. Nephrol Dial Transplant 27: 2642-2649, 2012.

2. Forbes JM and Cooper ME: Glycation in diabetic nephropathy. Amino Acids 42: 1185-1192, 2012.

3. Ramasamy R, Yan SF and Schmidt AM: The diverse ligand repertoire of the receptor for advanced glycation endproducts and pathways to the complications of diabetes. Vasc Pharmacol 57: $160-167,2012$.

4. Loeffler I and Wolf G: Transforming growth factor-beta and the progression of renal disease. Nephrol Dial Transplant 29 Suppl 1: i37-i45, 2014

5. Xie J, Méndez JD, Méndez-Valenzuela V and Aguilar-Hernández MM: Cellular signalling of the receptor for advanced glycation end products (RAGE). Cell Signal 25: 2185-2197, 2013.

6. Meek RL, LeBoeuf RC, Saha SA, et al: Glomerular cell death and inflammation with high-protein diet and diabetes. Nephrol Dial Transplant 28: 1711-1720, 2013.

7. Reddy MA, Sumanth P, Lanting L, et al: Losartan reverses permissive epigenetic changes in renal glomeruli of diabetic $\mathrm{db} / \mathrm{db}$ mice. Kidney Int) In press, 85: 362-373, 2013.

8. Forbes JM and Cooper ME: Mechanisms of diabetic complications. Physiol Rev 93: 137-188, 2013.

9. Wolf G: Cell cycle regulation in diabetic nephropathy. Kidney Int 58: S59-S66, 2000.

10. Kuan CJ, al-Douahji $\mathrm{M}$ and Shankland SJ: The cyclin kinase inhibitor p21WAF1, CIP1 is increased in experimental diabetic nephropathy: potential role in glomerular hypertrophy. J Am Soc Nephrol 9: 986-993, 1998.

11. Al-Douahji M, Brugarolas J, Brown PA, Stehman-Breen CO, Alpers CE and Shankland SJ: The cyclin kinase inhibitor p21WAF1/CIP1 is required for glomerular hypertrophy in experimental diabetic nephropathy. Kidney Int 56: 1691-1699, 1999.

12. Leclerc E, Fritz G, Vetter SW and Heizmann C: Binding of S100 proteins to RAGE: an update. Biochim Biophys Acta: 1793, 993-1007 2009.
13. Zimmer DB, Chessher J, Wilson GL and Zimmer WE: S100A1 and S100B expression and target proteins in type I diabetes. Endocrinol 138: 5176-5183, 1997.

14. Jung DH, Kim YS and Kim JS: KIOM-79 prevents S100b-induced TGF-betal and fibronectin expression in mouse mesangial cells. J Ethnopharmacol 125: 374-379, 2009.

15. Jung DH, Kim YS, Kim NH, Lee J, Jang DS and Kim JS: Extract of Cassiae Semen and its major compound inhibit S100b-induced TGF-beta1 and fibronectin expression in mouse glomerular mesangial cells. Eur J Pharmacol 641: 7-14, 2010.

16. Datto MB, Yu Y and Wang XF: Functional analysis of the transforming growth factor beta responsive elements in the WAF1/Cip1/p21 promoter. J Biol Chem 270: 28623-28628, 1995.

17. Michelson S, Alcami J, Kim SJ, et al: Human cytomegalovirus infection induces transcription and secretion of transforming growth factor beta 1. J Virol 68: 5730-5737, 1994.

18. Wrana JL, Attisano L, Cárcamo J, et al: TGF beta signals through a heteromeric protein kinase receptor complex. Cell 71: 1003-1014, 1992.

19. Baelde HJ, Eikmans M, Doran PP, Lappin DW, de Heer E and Bruijn JA: Gene expression profiling in glomeruli from human kidneys with diabetic nephropathy. Am J Kidney Dis: 43: 636-650, 2004.

20. Langer WJ, Devish K, Carmines PK and Lane PH: Prepubertal onset of diabetes prevents expression of renal cortical connective tissue growth factor. Pediatr Nephrol 23: 275-283, 2008.

21. Barrett T, Wilhite SE, Ledoux P, et al: NCBI GEO: archive for functional genomics data sets-update. Nucleic Acids Res 41: D991-D995, 2013.

22. Donato R, Sorci G, Riuzzi F, et al: S100B's double life: intracellular regulator and extracellular signal. Biochim Biophys Acta 1793: 1008-1022, 2009.

23. Kim SJ, Angel P, Lafyatis R, et al: Autoinduction of transforming growth factor beta 1 is mediated by the AP-1 complex. Mol Cell Biol 10: 1492-1497, 1990.

24. Isono M, Cruz MC, Chen S, Hong SW and Ziyadeh FN: Extracellular signal-regulated kinase mediates stimulation of TGF-beta1 and matrix by high glucose in mesangial cells. J Am Soc Nephrol 11: 2222-2230, 2000.

25. Burt DJ, Gruden G, Thomas SM, et al: P38 mitogen-activated protein kinase mediates hexosamine-induced TGFbetal mRNA expression in human mesangial cells. Diabetologia 46: 531-537, 2003.

26. Mu Y, Gudey SK and Landstrom M: Non-Smad signaling pathways. Cell Tissue Res 347: 11-20, 2012. 